\title{
Kemampuan Argumentasi Ilmiah Calon Guru IPA melalui Pendekatan MIKiR selama Pandemi Covid-19
}

\author{
D Diniya ${ }^{1 *}$, A Ilhami², Niki Dian Permana P3 ${ }^{3}$ I Mahartika ${ }^{4}$, Om Prakash ${ }^{5}$ \\ ${ }^{123}$ Program Studi Tadris IPA, Universitas Islam Negeri Sultan Syarif Kasim Riau \\ ${ }^{4}$ Program Studi Pendidikan Kimia, Universitas Islam Negeri Sultan Syarif Kasim Riau \\ ${ }^{3}$ Department of Mechanical Engineering, National Institute of Technology Patna \\ *Correspondence Address: diniya@uin-suska.ac.id
}

\begin{abstract}
Since the Covid-19 pandemic, learning at the university or school level has implemented online learning. Even though the learning is conducted online, the teacher candidate's scientific argumentation skills must be trained. One way is through the MIKIR approach. The purpose of this research is analyzing the science pre-service teachers' scientific argumentation skills by using MIKIR approach during pandemic covid-19. This type of research is a quasi-experimental study with a one-shot case study design. The research sample was 50 pre-service teachers. The instrument was an argumentation essay test based on the argumentation aspects according to Toulmin; claim, data, warrant and backing. The science pre-service teachers' scientific argumentation skills will be analyzed through the one-sample $T$ test assisted by the SPSS version 22 application. The results of this study is shown by the T score, $0.010>0.05$, is larger than a significance level. It means that MIKIR approach during pandemic covid-19 can practice significantly to the scientific argumentation skills of science pre-service teachers.
\end{abstract}

Keywords: science pre-service teachers' scientific argumentation skills, MIKIR approach, science learning during pandemic covid-19

\begin{abstract}
ABSTRAK
Sejak pandemi covid-19, pembelajaran baik di tingkat universitas atau sekolah menerapkan pembelajaran daring (online). Meskipun pembelajaran dilakukan secara daring, kemampuan argumentasi ilmiah calon guru IPA tetap harus dilatihkan. Salah satu caranya adalah melalui pendekatan MIKiR. Adapun tujuan penelitian ini adalah mengukur pengaruh pendekatan MIKiR dalam pembelajaran online terhadap kemampuan argumentasi ilmiah calon guru. Jenis penelitian ini adalah penelitian kuasi eksperimen dengan desain one-shot case study. Sampel penelitian adalah 50 calon guru IPA. Instrumen yang digunakan berupa tes argumentasi berupa soal esai berdasarkan aspek argumentasi menurut Toulmin; claim, data, warrant dan backing. Kemampuan argumentasi ilmiah calon guru IPA akan dideskripsikan dan dianalisis melalui uji $\mathrm{T}$ satu sampel berbantuan aplikasi SPSS versi 22. Hasil penelitian ditemukan skor uji T 0,010 > 0,05 yang artinya pendekatan MIKiR selama pandemi covid-19 dapat melatihkan kemampuan argumentasi calon guru IPA secara signifikan.
\end{abstract}

Kata kunci: kemampuan argumentasi ilmiah calon guru IPA, metode MIKiR, pembelajaran IPA selama pandemic covid-19

\section{PENDAHULUAN}

Pada abad 21 ini, teknologi terus berkembang dengan sangat pesat. Berkembangnya teknologi ini memberikan dampak ke berbagai aspek di kehidupan manusia tidak terkecuali di sektor pendidikan (Effendi \& Wahidy, 2019). Pada sektor pendidikan, secara spesifik terlihat adanya 
pergeseran dalam pembelajaran terutama dalam pembelajaran Ilmu Pengetahuan Alam (IPA). Pergeseran dalam pembelajaran IPA masa kini yaitu pembelajaran IPA tidak lagi hanya berupa transfer atau penguasaan ilmu pengetahuan berdasarkan fakta-fakta, konsep-konsep atau prinsipprinsip saja, tetapi juga terkait dengan mencari tahu tentang alam secara sistematis sebagai suatu proses penemuan sehingga peserta didik mampu memahami konsep melalui pengalaman langsung. Pembelajaran IPA masa kini juga bukan hanya untuk menguasai sejumlah pengetahuan, tetapi juga harus menyediakan ruang yang cukup untuk membangun kemampuan bernalar induktif, mengembangkan sikap ilmiah, meningkatkan pemahaman konsep, melalukan proses pemecahan masalah, dan menerapkannya melalui teknologi dalam kehidupan nyata. Selain itu, pembelajaran IPA masa kini ditandai dengan adanya penggunaan informasi, komputasi, teknologi dan komunikasi (Jacobsen, Eggen \& Kauchak, 2009; Diniya \& Rusdiana, 2018). Melalui pembelajaran IPA diharapkan peserta didik memenuhi kemampuan keterampilan belajar dan inovasi yang meliputi kemampuan berpikir dan kemampuan menyelesaikan masalah, kreatif dan inovatif, serta mampu berkomunikasi dan berkolaborasi (Bağ \& Çalik, 2017; Diniya, 2019). Dengan demikian, dapat dikatakan bahwa pemahaman konsep IPA saja belumlah cukup, masih dibutuhkan kemampuan lainnya berupa komunikasi dan kolaborasi yang mendukungnya.

Kemampuan komunikasi dan kolaborasi dapat ditunjukkan melalui kemampuan argumentasi yang dimiliki peserta didik (Aleixandre \& Rodriguez, 2000). Reformasi modern dalam pendidikan sains adalah menonjolkan konteks, kegiatan, dan percakapan ilmiah. Percakapan ilmiah dalam bentuk argumentasi ini sangat penting karena dianggap mampu meningkatkan pemahaman dan mengubah pemahaman sains Selaras dengan pernyataan yaitu (Moon et al., 2016). Para peneliti juga menyimpulkan bahwa menyediakan data ilmiah akan membantu peserta didik mengatasi kesulitan yang mereka alami dalam berargumentasi tentang topik ilmiah. Argumentasi ilmiah merupakan salah satu kriteria yang digunakan untuk menilai peserta didik dan telah ditekankan dalam Standar Nasional pendidikan IPA. Berland dan Hammer juga menyebutkan bahwa dalam beberapa tahun terakhir, argumentasi ilmiah telah semakin diakui sebagai praktek penting dalam pendidikan IPA karena memungkinkan peserta didik untuk aktif terlibat dalam menciptakan ide dan pertanyaan-pertanyaan melalui proses yang menghasilkan kemiripan dengan praktek-praktek ilmiah. Argumentasi ini sebagai mediator utama untuk mengakses pengetahuan (Berland \& Hammer, 2012). Oleh sebab itu, seorang calon guru IPA tentu juga harus memiliki kemampuan argumentasi sehingga nantinya dapat dilatihkan kepada peserta didik. Guru merupakan elemen penting dalam pembelajaran di kelas. Pengetahuan dan keterampilan tentang argumentasi ilmiah pada seorang guru akan sangat mempengaruhi keberhasilan dan kegagalan pembelajaran sains di dalam kelas (McNeill et al., 2016; Moon et al., 2016). Para guru harus menguasai beberapa keterampilan seperti keterampilan literasi digital, argumentasi ilmiah, berpikir kritis dan kolaborasi (Nova et al., 2020).

Berdasarkan penelitian yang telah banyak dilakukan menunjukkan bahwa tujuan pembelajaran dan kemampuan argumentasi yang dimiliki oleh seorang guru IPA sangat penting. Hal ini sejalan dengan penelitian yang dilakukan oleh McNeill et.al. kepada para guru terkait dengan investigasi terhadap faktor-faktor yang diyakini dapat mempengaruhi pembelajaran argumentasi. Pada penelitian tersebut ditemukan bahwa para guru yang menjadi responden mengatakan tujuan pembelajaran yang dikonstruk oleh seorang guru memberikan dampak yang besar dalam meningkatkan kemampuan argumentasi peserta didik. Para guru meyakini bahwa argumentasi menjadi tujuan pembelajaran yang sangat penting di samping pengetahuan yang dimiliki oleh peserta didik. Para guru juga masih banyak yang memperdebatkan tentang argumentasi dikarenakan pengetahuan dan kemampuan guru masih minim. Dengan demikian, seorang guru haruslah memahami tentang argumentasi (McNeill et al., 2016). Selaras dengan penelitian yang dilakukan oleh Lazarou et.al (2016) terkait dengan argumentasi ilmiah pada pembelajaran IPA adalah sebuah aktivitas sistematis. Pada penelitian tersebut ditemukan bahwa ada banyak guru yang tidak menggunakan metode pembelajaran yang sesuai untuk membangun 
keterampilan argumentasi peserta didik. Sebaiknya guru menerapkan metode pembelajaran yang membekas dalam diri peserta didik. Salah satu caranya adalah dengan melakukan argumentasi antar peserta didik. Selain itu, ditemukan juga mungkin yang menjadi kendala adalah kekurangan waktu dan beban kerja guru yang berat (Lazarou et al., 2016). Penelitian yang dilakukan oleh Pratiwi menyebutkan bahwa seorang guru selain dapat menguasai suatu model pembelajaran juga harus dapat mengintegrasikan argumentasi ilmiah dalam model pembelajaran (Pratiwi et al., 2019).

Berdasarkan hasil observasi kepada 26 calon guru IPA di Prodi Tadris IPA, diperoleh bahwa pengetahuan tentang argumentasi ilmiah masih minim. Bahkan komponen terkait argumentasi masih kurang dipahami oleh para calon guru tersebut. Hal itu menyebabkan para calon guru IPA masih kesulitan dalam mengkonstruksi argumentasi tertulis ataupun lisan terutama dalam mendukung klaim dan data. Dengan demikian, dibutuhkan sebuah metode yang mampu menggali keterampilan argumentasi ilmiah calon guru IPA tersebut. Ditambah lagi, berdasarkan hasil observasi lapangan pada 20 orang guru IPA, selama pandemi covid-19 pembelajaran IPA terkendala dalam kegiatan praktikum. Para guru membutuhkan inovasi agar praktikum tetap dilakukan meskipun secara daring.

Argumentasi bukan hanya satu bagian yang terpisah dalam pembelajaran. Argumentasi merupakan sebuah aktivitas sistematis yang dimulai dari pengetahuan dan keterampilan guru akan argumentasi tersebut. Adanya pengetahuan dan keterampilan argumentasi dalam diri seorang guru ataupun calon guru dapat ditunjukkan dari cara guru memilih metode dalam pembelajaran. Pemilihan metode pembelajaran menemukan langsung akan sangat mempengaruhi keterampilan argumentasi seperti model pembelajaran inkuiri dan Problem Based Learning (PBL) (Diniya, 2019; Diniya et al., 2019; Lazarou et al., 2016, 2017; Pratiwi et al., 2019). Metode MIKIR yang dikembangkan oleh Tanoto Foundation dengan maksud agar pembelajar (subjek belajar) mampu diajak untuk kreatif, kolaborasi, komunikasi dan kerjasama dalam tim, serta bersikap kritis selama proses pembelajaran berlangsung (Pernantah, 2019). Hal ini akan sangat berguna jika dilatihkan kepada calon guru IPA karena selama ini banyak peserta didik yang sangat minim kemampuan argumentasi ilmiahnya. Dengan demikian, sangat penting jika dimulai dari melatih kemampuan argumentasi ilmiah kepada calon gurunya sehingga nanti guru tersebut dapat juga melatihkan kepada peserta didik. Perlu strategi pembelajaran aktif untuk meningkatkan hal itu agar semua calon guru terlibat aktif dalam semua kegiatan pembelajaran IPA terutama di masa pembelajaran daring.

Sampai saat ini, kemampuan berargumentasi mendapat perhatian khusus dari banyak peneliti pendidikan (Ozdem, Ertepinar, Cakiroglu \& Erduran, 2013, hlm. 2559; Gultepe \& Kilij, 2014, hlm. 4). Penelitian tentang keterampilan argumentasi seorang guru masih sedikit (Lazarou et al., 2016) sehingga peneliti bertujuan untuk menganalisis kemampuan argumentasi ilmiah calon guru IPA melalui pendekatan MIKiR selama pandemi covid-19. Adapun konteks kajian pada penelitian ini terkait dengan kemampuan argumentasi ilmiah calon guru IPA. Selanjutnya, pada penelitian ini akan membahas kemampuan argumentasi ilmiah calon guru IPA dengan menggunakan pendekatan MIKiR yang merupakan salah satu pendekatan saintifik. Pendekatan saintifik merupakan acuan dalam pembelajaran IPA (Ardaya, 2016; Istiqomah \& Ramli, 2019; Rohmawati, 2018; Syafaren et al., 2019).

\section{METODOLOGI}

Jenis penelitian ini menggunakan penelitian kuasi eksperimen dengan menggunakan OneShot Case Study (Studi Kasus Satu Tembakan). Jenis penelitian ini digunakan karena penelitian ini tidak menggunakan kelas kontrol. Gambaran kemampuan argumentasi ilmiah calon guru IPA secara kuantitatif didapat dengan menggunakan desain the one-shot case study (Fraenkel \& Wallen, 2012). Pada penelitian ini digunakan satu kelompok yang akan diberikan perlakuan dan postest. 
Tabel 1. Desain Penelitian the One-Shot Case Study

\begin{tabular}{ccc}
\hline Group & Treatment & Posttest \\
\hline Treatment Group & $\mathrm{X}$ & $\mathrm{O}$ \\
\hline
\end{tabular}

keterangan:

$\mathrm{X} \quad$ : metode MIKiR dalam pembelajaran online

$\mathrm{O} \quad$ : kemampuan argumentasi ilmiah calon guru

Variabel bebas dalam penelitian ini adalah model pembelajaran sedangkan variabel terikatnya adalah kemampuan argumentasi ilmiah. Populasi adalah kelompok besar dimana sampel diambil dan diharapkan hasil penelitian dapat digeneralisasikan ke populasi. Sampel adalah orang atau obyek lain yang diambil dari populasi yang diminati dengan tujuan untuk dipelajari. Sampel harus merepresentasikan populasi atau dapat mewakili populasi (Fraenkel \& Wallen, 2012). Adapun populasi dalam penelitian ini adalah seluruh calon guru dinprodi Tadris IPA UIN Suska Riau. Pemilihan sampel dalam penelitian ini diambil melalui teknik purposive sampling yaitu pemilihan sampel secara sengaja. Adakalanya suatu kondisi yang tidak memungkinkan untuk mengacak keseluruhan orang dari populasi yang ada. Pemilihan sampel acak biasa dan berstrata tidak dapat digunakan disebabkan adanya administrasi atau keterbatasan lainnya (Fraenkel \& Wallen, 2012).. Adapun jumlah sampel pada penelitian ini sebanyak 50 orang calon guru IPA.

Instrumen penelitian adalah alat pengumpul data dalam penelitian (Fraenkel, Wallen, \& Hyun, 2012; Sudjana \& Ibrahim, 2014). Pada penelitian ini, sebelum data-data diperoleh terlebih dahulu dibuat instrumen penelitian berupa instrumen tes. Instrumen tes yang digunakan dalam penelitian adalah tes kemampuan argumentasi. Tes yang diberikan untuk mengukur kemampuan argumentasi ilmiah berupa soal uraian sebanyak 4 item dengan masing-masing sub-soal sebanyak 4 item. Tes kemampuan argumentasi ilmiah diberikan pada akhir pembelajaran mengenai topik kelistrikan. Tes akhir (posttest) dilakukan pada akhir pembelajaran setelah diberikannya perlakuan (treatment). Penyusunan soal tes berpedoman pada silabus topik kelistrikan. Adapun desain pembelajaran pendekatan MIKiR adalah sebagai berikut

Tabel 2. Desain Pembelajaran Pendekatan MIKiR

\begin{tabular}{|c|c|c|c|}
\hline $\begin{array}{c}\text { Unsur Belajar } \\
\text { Aktif }\end{array}$ & Kegiatan & Pengelolaan Kelas & Waktu \\
\hline Mengalami & $\begin{array}{l}\text { Calon guru melakukan pengamatan terhadap } \\
\text { masalah yang diberikan }\end{array}$ & Kelompok & $20^{\prime}$ \\
\hline \multirow[t]{3}{*}{ Interaksi } & $\begin{array}{l}\text { Pada saat melakukan pengamatan para anggota } \\
\text { kelompok saling mengemukakan pendapatnya } \\
\text { dalam fitur breakout room Zoom. }\end{array}$ & Kelompok & $30^{\prime}$ \\
\hline & $\begin{array}{l}\text { Pada bagian ini, setiap individu melakukan } \\
\text { pengamatan dan kegiatan praktikum } \\
\text { dilaksanakan di tempatnya masing-masing. }\end{array}$ & & \\
\hline & $\begin{array}{l}\text { Hasil pengamatan dituliskan di dalam Lembar } \\
\text { Kerja. Masing-masing calon guru IPA dalam } \\
\text { kelompoknya melakukan analisis dan diskusi } \\
\text { berdasarkan hasil pengamatan }\end{array}$ & & \\
\hline Komunikasi & $\begin{array}{l}\text { Masing-masing kelompok mengemukakan hasil } \\
\text { pengamatannya di depan kelompok lain. } \\
\text { Kelompok lainnya memberikan pertanyaan dan } \\
\text { tanggapan }\end{array}$ & Kelompok & $40^{\prime}$ \\
\hline Refleksi & $\begin{array}{l}\text { Menuliskan apa saja yang telah dipelajari, apa } \\
\text { yang ingin diketahui lebih lanjut, apa yang } \\
\text { didapat selama belajar }\end{array}$ & Individu & $10^{\prime}$ \\
\hline
\end{tabular}




\section{TEMUAN DAN PEMBAHASAN}

Hasil penilaian keterampilan argumentasi ilmiah calon guru IPA ditunjukkan oleh skor hasil postes keterampilan argumentasi ilmiah setelah diterapkannya pendekatan MIKiR. Rata-rata skor keterampilan argumentasi ilmiah calon guru IPA ditunjukkan pada Tabel 3.

Tabel 3. Data Postes Keterampilan Argumentasi Ilmiah Calon Guru IPA

\begin{tabular}{ccccccc}
\hline & N & Rata-rata & $\begin{array}{c}\text { Std. } \\
\text { Deviasi }\end{array}$ & $\begin{array}{c}\text { Std. Error } \\
\text { Mean }\end{array}$ & $\begin{array}{c}\text { Nilai } \\
\text { Minimum }\end{array}$ & $\begin{array}{c}\text { Nilai } \\
\text { Maksimum }\end{array}$ \\
\hline Kelompok & 52 & 79.2692 & 9.78618 & 1.35710 & 62 & 100 \\
\hline
\end{tabular}

Berdasarkan Tabel 3 ditemukan nilai rata-rata skor postes sebesar 79,26, nilai standar deviasi berada pada angka 9,78 dan nilai standar eror rata-rata sebesar 1,35.

Tabel 4. Hasil Uji Normalitas Keterampilan Argumentasi Ilmiah Calon Guru IPA

\begin{tabular}{ccccc}
\hline Kemampuan Argumentasi & \multicolumn{3}{c}{ Shapiro-Wilk } & \\
Ilmiah & Statistik & df & Sig. & Keterangan \\
\hline Tes akhir (posttest) & 0,968 & 52 & 0,180 & Normal \\
\hline
\end{tabular}

Berdasarkan Tabel 4, nilai postes kemampuan argumentasi memiliki nilai signifikansi 0,180. Nilai tersebut lebih besar dari nilai signifikansi alpha $(\alpha=0,05)$ yang berarti terjadi penerimaan $\mathrm{H}_{0}$ dan data berdistribusi normal.

Tabel 5. Hasil Uji T Satu Sampel

\begin{tabular}{|c|c|c|c|}
\hline Kriteria Uji Hipotesis & Uji & Signifikansi & Keputusan \\
\hline $\begin{array}{l}\mathrm{H}_{0} \text { : } \\
\text { Tidak terdapat pengaruh pendekatan } \\
\text { MIKiR terhadap kemampuan } \\
\text { argumentasi ilmiah calon guru IPA } \\
\mathrm{H}_{\mathrm{a}} \text { : } \\
\text { Terdapat pengaruh pendekatan } \\
\text { MIKiR terhadap kemampuan } \\
\text { argumentasi ilmiah calon guru IPA }\end{array}$ & $\begin{array}{c}\text { Uji T satu } \\
\text { sampel }\end{array}$ & 0,010 & Menerima $\mathrm{H}_{2}$ \\
\hline
\end{tabular}

Nilai signifikansi yang ditunjukkan pada Tabel 5 lebih kecil dari nilai signifikansi alpha $(\alpha=0,05)$ yaitu $0,010>0,05$ sehingga terjadi penerimaan $H_{a}$, artinya dapat disimpulkan bahwa terdapat pengaruh pendekatan MIKiR terhadap kemampuan argumentasi ilmiah calon guru IPA selama pandemi covid-19.

\section{Pembahasan}

Secara keseluruhan, keterampilan argumentasi ilmiah calon guru IPA termasuk dalam kategori baik yaitu dengan nilai rata-rata 79, 269. Selain itu pendekatan MIKiR dalam pembelajaran online memiliki pengaruh terhadap kemampuan argumentasi ilmiah calon guru IPA. Para calon guru harus dapat menjelaskan konsep dengan kalimat mereka sendiri, meminta bukti dan klarifikasi dari penjelasan mereka, dan mengarahkan kegiatan diskusi. Pada tahap interaksi, komunikasi dan refleksi sangat membantu melatihkan kemampuan argumentasi ilmiah para calon guru. Sangat penting melatihkan kemampuan argumentasi kepada calon guru agar dapat melatihkannya kepada peserta didik. Penelitian terkait kemampuan argumentasi ilmiah pada calon guru juga penting untuk dilakukan karena masih minimnya penelitian terkait hal tersebut.

Pendekatan MIKiR merupakan salah satu pembelajaran aktif (active learning) (Pernantah, 2019). Pembelajaran dengan pendekatan MIKiR dapat mendorong para calon guru IPA agar 
lebih aktif, kritis, inovatif dan komunikatif. Sebab, metode MIKIR ini akan menuntut mcalon guru IPA lebih aktif terlibat dalam upaya melakukan percobaan, pengamatan dan pengolahan informasi. Calon guru IPA melakukan percobaan di rumahnya masing-masing namun terkoneksi dengan breakout room yang ada dalam fitur Zoom Cloud Meeting. Meskipun semua melakukan praktikum di rumah namun dapat dilihat secara bersamaan di waktu yang sama. Teman yang lain dapat memberikan pandangan terhadap hasil pengamatan yang dilakukan. Kemudian calon guru IPA harus mampu bekerjasama dan kolaborasi dalam suatu kelompok untuk mendiskusikan hasil percobaan. Hasil percobaan dituliskan dalam lembar kerja yang sudah dibagikan kemudian mempresentasikan hasil kerja samanya di hadapan para calon guru IPA lainnya. Para calon guru IPA lainnya memberikan tanggapan terhadap hasil diskusi. Kegiatan tersebut sangat mendorong para guru untuk membangkitkan dan melatihkan kemampuan argumentasi ilmiah yang dimilikinya. Selain itu, tentu hal ini relevan bagi para calon guru yang juga dapat mempelajari metode ini untuk nantinya bisa diimplementasikan pada saat telah menjadi guru di sekolah. Adapun keterbatasan penelitian ini adalah peneliti belum meneliti terkait dengan kemampuan argumentasi ilmiah para calon guru berdasarkan setiap aspek argumentasi ilmiah. Maka implikasi penelitian ini adalah para calon guru hendaknya memahami secara mendalam akan pentingnya kemampuan argumentasi terutama dalam dirinya sendiri dengan cara sering berlatih. Salah satu pendekatan yang dapat digunakan adalah melalui pendekatan MIKiR. Adanya pengetahuan dan kemampuan guru tentang argumentasi ilmiah maka guru akan mudah melatihkan kemampuan argumentasi ilmiah kepada para peserta didik. Guru juga hendaknya menyadari perannya sebagai fasilitator dalam pembelajaran dengan cara memberikan kesempatan seluas-luasnya kepada peserta didik untuk memberikan argumentasi ilmiah. Dengan demikian, tidak hanya kemampuan argumentasi ilmiah guru yang terlatih namun juga peserta didik.

\section{SIMPULAN}

Berdasarkan hasil penelitian ditemukan bahwa pembelajaran pendekatan MIKiR selama pandemi covid-19 dapat melatihkan kemampuan argumentasi ilmiah calon guru IPA. Langkah interaksi dan komunikasi dalam pendekatan MIKiR sangat membantu dalam melatihkan kemampuan argumentasi ilmiah calon guru IPA. Penelitian terkait dengan kemampuan argumentasi ilmiah para guru masih sangat sedikit. Dengan demikian dibutuhkanya penelitian lebih lanjut terkait dengan hal tersebut. Adapun keterbatasan penelitian ini adalah peneliti belum meneliti terkait dengan kemampuan argumentasi ilmiah para calon guru berdasarkan setiap aspek argumentasi ilmiah.

\section{REFERENSI}

Alexaindre, J. \& Rodriguez, A.B. (2000). Doing the Lesson or Doing Science: Argument in High School Genetics. John Wiley \& Sons, Inc.

Ardaya, D. A. (2016). Penerapan Pendekatan Saintifik Untuk Meningkatkan Pemahaman Konsep Materi Ipa Siswa Sekolah Dasar. Jurnal Pendidikan Guru Sekolah Dasar, 1(1), 72-83. https://doi.org/10.17509/jpgsd.v1i1.9065

Bağ, H., \& Çalik, M. (2017). A thematic review of argumentation studies at the K-8 level. Egitim ve Bilim, 42(190), 281-303. https://doi.org/10.15390/EB.2017.6845

Berland, L. K., \& Hammer, D. (2012). Framing for scientific argumentation. Journal of Research in Science Teaching, 49(1), 68-94. https://doi.org/10.1002/tea.20446 
Diniya, D. (2019). An Investigation of Scientific Argumentation Skills by using Analogical Mapping-based on Inquiry Learning between Experiment and Control Group. 329-335.

Diniya, D., Rusdiana, D., \& Hernani, H. (2019). Promoting coupled-inquiry cycle through shared curricular integration models to enhance students argumentation. Journal of Physics: Conference Series, 1157(2). https://doi.org/10.1088/1742-6596/1157/2/022029

Diniya, \& Rusdiana, D. (2018). Improving Students' Argumentation by Providing Analogical Mapping-Based Through Lab Inquiry for Science Class. IOP Conference Series: Materials Science and Engineering, 288(1). https://doi.org/10.1088/1757-899X/288/1/012053

Effendi, D., \& Wahidy, A. (2019). Pemanfaatan Teknologi dalam Proses Pembelajaran Menuju Pembelajaran Abad 21. Pemanfaatan Teknologi Dalam Proses Pembelajaran Menuju Pembelajaran Abad 21, 2, 125-129. 21 https://jurnal.univpgripalembang.ac.id/index.php/Prosidingpps/article/view/2977/2799

Fraenkel, Wallen \& Hyun. (2012). How to Design and Evaluate Research in Education (Eight Edition). New York: McGraw Hill International Edition

Gultepe, N. \& Kose, M. (2016). Which is More Effective: In Groups or as Individuals?. (Online). Diunduh dari https://www.researchgate.net/publication/303820799_WHICH_IS_MORE_EFFECTIVE _IN_GROUPS_OR_AS_INDIVIDUALS pada 5 Desember 2017.

Jacobsen, D.A., Eggen P. \& Kauchak D. (2009). Methods for Teaching: Promoting Student Learning in K-12 Classroom. New Jersey: Pearson.

Lazarou, D., Erduran, S., \& Sutherland, R. (2017). Argumentation in science education as an evolving concept: Following the object of activity. Learning, Culture and Social Interaction, 14(May), 51-66. https://doi.org/10.1016/j.lcsi.2017.05.003

Lazarou, D., Sutherland, R., \& Erduran, S. (2016). Argumentation in science education as a systemic activity: An activity-theoretical perspective. International Journal of Educational Research, 79, 150-166. https://doi.org/10.1016/j.ijer.2016.07.008

McNeill, K. L., Katsh-Singer, R., González-Howard, M., \& Loper, S. (2016). Factors impacting teachers' argumentation instruction in their science classrooms. International Journal of Science Education, 38(12), 2026-2046. https://doi.org/10.1080/09500693.2016.1221547

Moon, A., Stanford, C., Cole, R., \& Towns, M. (2016). The nature of students' chemical reasoning employed in scientific argumentation in physical chemistry. Chemistry Education Research and Practice, 17(2), 353-364. https://doi.org/10.1039/c5rp00207a

Nova, T. L., Ilhami, A., Islam, U., Sultan, N., \& Kasim, S. (2020). Analysis of Pre-service Science Teachers 'Digital Literacy Through Workshop of Optimization Microsoft Office Software Usage. 3(1), 70-78.

Pernantah, P. S. (2019). Desain Skenario Pembelajaran Aktif Dengan Metode "Mikir" Pada Mata Kuliah Pendidikan IPS. Indonesian Journal of Social Science Education (IJSSE), 1(2), 145-155. 
Pratiwi, S. N., Cari, C., Aminah, N. S., \& Affandy, H. (2019). Problem-Based Learning with Argumentation Skills to Improve Students' Concept Understanding. Journal of Physics: Conference Series, 1155(1). https://doi.org/10.1088/1742-6596/1155/1/012065

Rohmawati, S. S. S. (2018). Penerapan Pendekatan Saintifik pada Mata Pelajaran IPA di MTs Putri Nurul Masyithoh Lumajang. Jurnal Kajian Teknologi Pendidikan, 1, 205-212. http://journal2.um.ac.id/index.php/jktp/article/view/4543

Sudjana, N., Ibrahim. (2014). Penelitian dan Penilaian Pendidikan. Bandung:Sinar Baru Algesindo.

Syafaren, A., Yustina, Y., \& Mahadi, I. (2019). Pembelajaran Ipa Berbasiskan Integrasi Inkuiri Terbimbing Dengan Numbered Heads Together (Nht) Dalam Meningkatkan Motivasi Belajar. Journal of Natural Science and Integration, 2(1), 1. https://doi.org/10.24014/jnsi.v2i1.7109 